Check for updates

Cite this: J. Mater. Chem. A, 2019, 7, 10483

Received 26th February 2019

Accepted 9th March 2019

DOI: 10.1039/c9ta02166c

rsc.li/materials-a

\title{
Theoretical tuning of Ruddlesden-Popper type anti-perovskite phases as superb ion conductors and cathodes for solid sodium ion batteries $\uparrow$
}

\begin{abstract}
Yuran Yu, (D) ab Zhuo Wang (D)*ab and Guosheng Shao (D) *ab
It is very important and yet extremely challenging to develop solid-state electrolytes for safe sodium ion batteries, largely due to sodium ions being significantly larger than lithium ones. Here in this work we have carried out systematic modelling, using a materials genome approach in the framework of density functional theory (DFT), to formulate a new system of ion conductors and compatible cathodes. Through iso-valent substitution of both the anion and cation sites in a $\mathrm{Na}_{4} \mathrm{Ol}_{2}$ compound with a Ruddlesden-Popper type phase based on sheets of anti-perovskite structural units, or an antiRuddlesden-Popper phase (ARP), we have identified a series of stable layer-structured phases, with the general formula $\mathrm{Na}_{4-c} \mathrm{Li} \mathrm{i}_{C} \mathrm{AX}_{4}(\mathrm{~A}=\mathrm{O}$ and/or $\mathrm{S} ; \mathrm{X}=1$ and/or $\mathrm{Cl})$, as remarkable electrolytes and high capacity cathodes to enable solid sodium ion batteries. The optimized $\mathrm{Na}_{3} \mathrm{LiS}_{0.5} \mathrm{O}_{0.5} \mathrm{I}_{2}$ compound is a marvellous $\mathrm{Na}^{+}$conductor, with an extremely low activation energy for $\mathrm{Na}^{+}$transportation $(0.12 \mathrm{eV})$ and a high $\mathrm{Na}^{+}$conductivity of $6.3 \mathrm{mS} \mathrm{cm}^{-1}$ at standard room temperature (298 K). This superb solid electrolyte does not react with the sodium anode, and formation of layer-structured phases due to its sodium depletion leads to compatible cathode materials with high voltage plateaus to enable full batteries with high energy densities.
\end{abstract}

\section{Introduction}

With ever pressing needs for high performance metal ion batteries essential to modern society, ${ }^{1-3}$ greater and greater efforts have been directed towards developing alternative metal ion batteries ${ }^{4-8}$ beyond Li-ion batteries (LIBs), due to limited lithium resources. Naturally, sodium-ion batteries (SIBs) are among the most attractive ones, owing to the nearly inexhaustible resource of sodium and its much lower price. ${ }^{9}$ One of the main areas of focus in SIBs lies in developing safer electrolytes, as current liquid organic electrolytes are rather flammable..$^{10-14}$ Such a drawback needs to be overcome before the technology can take off for wide applications, since SIBs are more suitable for application in large scale energy storage due to their less competitive energy density than LIBs, ${ }^{4,15}$ thus making the safety requirement even more demanding. Indeed, safety issues are one of the major generic concerns for secondary metal ion batteries based on liquid organic electrolytes, ${ }^{12}$ which is the very driving factor in developing solid-state

${ }^{a}$ State Center for International Cooperation on Designer Low-carbon \& Environmental Materials (CDLCEM), Zhengzhou University, 100 Kexue Avenue, Zhengzhou 450001, China

${ }^{b}$ Zhengzhou Materials Genome Institute (ZMGI), Zhongyuanzhigu, Building 2, Xingyang 450100, China.E-mail: gsshao@zzu.edu.cn; wangzh@zzu.edu.cn

$\dagger$ Electronic supplementary information (ESI) available. See DOI: $10.1039 / \mathrm{c} 9 \mathrm{ta} 02166 \mathrm{c}$ batteries employing non-flammable inorganic solid-state electrolytes (SSEs). ${ }^{10,11,15}$ From the end users' point of view, an ideal SSE for SIBs is expected to meet the following criteria ${ }^{16}$ : (a) high $\mathrm{Na}^{+}$conductivity greater than $1 \mathrm{mS} \mathrm{cm}{ }^{-1}$; (b) electrically insulating to avoid self-discharging in batteries; (c) structurally/ energetically stable to safeguard dependable service in a wide temperature range, e.g. from -50 to $250{ }^{\circ} \mathrm{C}$; (d) electrochemically compatible with the sodium anode, so as to make use of the highest energy density of sodium $\left(1.16 \mathrm{~A} \mathrm{~h} \mathrm{~g}^{-1}\right)$; and (e) light weight, economical, and environmentally friendly.

As sodium and lithium are neighbouring alkali metals with similar chemical properties, knowledge on solid lithium conductors has been naturally extended into developing solid electrolytes for SIBs, ${ }^{11,12,17-19}$ in particular through straightforward substitution of $\mathrm{Li}$ by $\mathrm{Na}$ in known SSEs for LIBs. ${ }^{15}$ However, distinct differences exist between $\mathrm{Na}^{+}$and $\mathrm{Li}^{+}$ions. $\mathrm{Na}^{+}$ions are about $26 \%$ larger than $\mathrm{Li}^{+}$ions (ionic radii $1.02 \AA$ vs. $0.76 \AA$, respectively), ${ }^{4,15}$ and they are also much heavier $(23 \mathrm{~g}$ $\mathrm{mol}^{-1}$ of $\mathrm{Na}^{+}$vs. $6.9 \mathrm{~g} \mathrm{~mol}^{-1}$ of $\left.\mathrm{Li}^{+}\right){ }^{15}$ Furthermore, the standard electrode potential of sodium $(-2.71 \mathrm{~V} v s$. standard hydrogen electrode, SHE $)$ is higher than that of lithium $(-3.05 \mathrm{~V} v s$. SHE $){ }^{4}$ Such major differences contribute to the greater difficulty in developing solid electrolytes with superb $\mathrm{Na}^{+}$conductivity to rival liquid electrolytes.

Great efforts have been made to develop potential SSEs for SIBs based on sulfides. ${ }^{13} \mathrm{Na}^{+}$conductivity in $\mathrm{Na}_{10} \mathrm{SnP}_{2} \mathrm{~S}_{12},{ }^{19}$ by replacing $\mathrm{Li}$ with $\mathrm{Na}$ in $\mathrm{Li}_{10} \mathrm{GeP}_{2} \mathrm{~S}_{12}$ (LGPS), was $0.4 \mathrm{mS} \mathrm{cm}^{-1}$ at 
room temperature, which is lower than the critical request of 1 $\mathrm{mS} \mathrm{cm}^{-1}$. The activation barrier for $\mathrm{Na}^{+}$diffusion in $\mathrm{Na}_{10^{-}}$ $\mathrm{SnP}_{2} \mathrm{~S}_{12}$ was also too high $(0.356 \mathrm{eV})$. Subsequently, $\mathrm{Na}^{+}$transportation was improved significantly through the slight stoichiometric offset with excess $\mathrm{Na}$, so that the activation energy for $\mathrm{Na}^{+}$diffusion in $\mathrm{Na}_{11} \mathrm{Sn}_{2} \mathrm{PS}_{12}$ (ref. 20) was lowered to $0.25 \mathrm{eV}$. The total ionic conductivity reached $1.4 \mathrm{mS} \mathrm{cm}^{-1}$ at room temperature, which is still marginal for a competitive solid electrolyte to function adequately below $0{ }^{\circ} \mathrm{C}$. Furthermore, due to the inheritance of the tetrahedral $\mathrm{PS}_{4}$ and $\mathrm{SnS}_{4}$ units from the LGPS system, ${ }^{17,18}$ the electrolyte is not compatible with the $\mathrm{Na}$ anode, with a tendency to be decomposed into $\mathrm{Na}_{x} \mathrm{P}, \mathrm{Na}_{2} \mathrm{~S}$ etc. ${ }^{20,21}$ The stability window of $\mathrm{Na}_{11} \mathrm{Sn}_{2} \mathrm{PS}_{12}$ is only $0.57 \mathrm{~V}$ (from 1.25 to $1.82 \mathrm{~V}$ vs. Na), which cannot prevent undesirable interphase formation below $1.25 \mathrm{~V}$ with the $\mathrm{Na}$ anode, or above $1.82 \mathrm{~V}$ with the cathode. The narrow electrochemical window and the incompatibility with the Na anode for $\mathrm{Na}_{11} \mathrm{Sn}_{2} \mathrm{PS}_{12}$ would significantly hinder construction of all-solid SIBs with sodium anodes for high energy density.

A narrow electrochemical window is one of the major shortcomings for alkali-metal phosphor-sulfides. ${ }^{22-28}$ It is highly encouraging to notice that sodium hali-oxides such as $\mathrm{Na}_{3} \mathrm{OX}$ with cubic anti-perovskite structures are compatible with $\mathrm{Na}$ anodes (X: halogen). ${ }^{29}$ More intriguingly, a layered $\mathrm{Na}_{4} \mathrm{OI}_{2}$ compound was found to be stable at room temperature. Such a layered phase belongs to the anti-perovskite group, containing plenty of $\mathrm{Na}^{+}$ions with a $57 \%$ atomic percentage in its unit cell. ${ }^{29-31}$ However, experimental studies revealed that the $\mathrm{Na}^{+}$ conductivity in $\mathrm{Na}_{4} \mathrm{OI}_{2}$ was too poor, only $0.03 \mathrm{mS} \mathrm{cm}{ }^{-1}$ even at an elevated temperature of $180{ }^{\circ} \mathrm{C} .{ }^{32}$ It is therefore highly useful to devise a theoretical roadmap to guide effective tuning of materials chemistry of $\mathrm{Na}_{4} \mathrm{OI}_{2}$ based materials, so that practical delivery of superb $\mathrm{Na}^{+}$conductors can be achieved costeffectively, thus enabling high-performance solid state SIBs.

Here in this work, we have carried out systematic modelling on the basis of a materials genome approach in the framework of density functional theory (DFT). ${ }^{7,16,18,33-35}$ On the basis of a high throughput simulation, we have identified effective routes for remarkable enhancement of ionic conductivity, based on $\mathrm{Na}_{4} \mathrm{AX}_{2}(\mathrm{~A}=$ chalcogen and $\mathrm{X}=$ halogen $)$. This covers the effects of smaller halogen anions on the $\mathrm{X}$ sites, substitution of $\mathrm{O}^{-2}$ with chalcogen species with weaker electronegativities on the A sites, and co-alloying on both the A and X sites. Through extensive screening of numerous structural configurations, we have identified the best sodium hali-chalcogenide candidate with the stoichiometry of $\mathrm{Na}_{4} \mathrm{~S}_{0.5} \mathrm{O}_{0.5} \mathrm{I}_{2}$, which is thermodynamically and dynamically stable. The ionic conductivity of $\mathrm{Na}_{4} \mathrm{~S}_{0.5} \mathrm{O}_{0.5} \mathrm{I}_{2}$ reaches $0.347 \mathrm{mS} \mathrm{cm}^{-1}$ with a moderate activation energy $E_{\mathrm{a}}$ of $0.23 \mathrm{eV}$. More importantly, through the replacement of a quarter of the $\mathrm{Na}^{+}$site by $\mathrm{Li}^{+}$, we have identified a hybrid SSE of $\mathrm{Na}_{3} \mathrm{LiS}_{0.5} \mathrm{O}_{0.5} \mathrm{I}_{2}$ as a superb $\mathrm{Na}^{+}$conductor, which permits $\mathrm{Na}^{+}$conductivity up to $6.3 \mathrm{mS} \mathrm{cm}^{-1}$ at $25{ }^{\circ} \mathrm{C}$, together with an extremely low activation energy of $0.12 \mathrm{eV}$. Such high performance and electrochemical compatibility with the sodium anode is to provide a fundamentally solid basis to enable high ionic conductivity well below $0{ }^{\circ} \mathrm{C}$, which is key for high performance solid SIBs.

\section{Methods}

Theoretical calculations were performed using the Vienna Ab Initio Simulation Package (VASP), ${ }^{36,37}$ with the ionic potentials including the effect of core electrons being described by the projector augmented wave (PAW) method. ${ }^{38,39}$ In this work, the Perdew-Burke-Ernzerhof (PBE) exchange-correlation (XC) functionals ${ }^{\mathbf{4 0 , 4 1}}$ are used to study the structural stabilities of the $\mathrm{Na}_{4} \mathrm{AX}_{2}$ family. For geometric relaxation of the structures, summation over the Brillouin Zone (BZ) is performed with Monkhorst-Pack $k$-point intervals limited below $0.04 \AA^{-1}$ for both conventional and primitive cells. ${ }^{42}$ A plane-wave energy cutoff of $600 \mathrm{eV}$ was used in all calculations. All structures were geometrically relaxed until the total force on each ion was reduced below $0.01 \mathrm{eV} \AA^{-1} \cdot{ }^{43-45}$ For the calculations of electronic energy band structures, we used the HSE06 functional to predict more accurate values of band gaps. ${ }^{46,47}$ We employed a convergence criterion of $10^{-6} \mathrm{eV}$, adequate for electronic selfconsistent cycles.

The universal structure predictor (USPEX) ${ }^{\mathbf{4 8 , 4 9}}$ based on energy minimization was employed to predict stable or metastable structures for any given composition. For each composition, a population of 230 possible structures was randomly created with varied symmetries in the first generation. When the full structure relaxation was reached, the most stable and metastable structures, through the comparison of enthalpy of formation, were placed into the next generation. Afterwards, each subsequent generation would be created through heredity, with lattice mutation and permutation operators being applied and assessed energetically for the selection of a population of 60 for the next run. USPEX would continue screening the structures until the most stable configuration remained unchanged for a further 20 generations to safeguard the global equilibrium. ${ }^{34}$

The energy (enthalpy) of formation of each $\mathrm{Na}_{a} \mathrm{~S}_{b} \mathrm{O}_{c} \mathrm{I}_{d} \mathrm{Cl}_{e}$ compound was defined with respect to the chemical potentials of the constituent phases as

$$
E_{\mathrm{f}}=E_{\mathrm{c}}-b E_{\mathrm{Na}_{2} \mathrm{~S}}-c E_{\mathrm{Na}_{2} \mathrm{O}}-d E_{\mathrm{NaI}}-e E_{\mathrm{NaCl}}
$$

where $E_{\mathrm{c}}$ is the total energy of the compound and $E_{\mathrm{Na}_{2} \mathrm{~S}}, E_{\mathrm{Na}_{2} \mathrm{O}}$, $E_{\mathrm{NaI}}$, and $E_{\mathrm{NaCl}}$ are total energies of $\mathrm{Na}_{2} \mathrm{~S}, \mathrm{Na}_{2} \mathrm{O}, \mathrm{NaI}$, and $\mathrm{NaCl}$ respectively (we used the ground state stable structure as a reference for each element/constituent as listed in the Materials Project webpage https:/www.materialsproject.org. The energy of formation with respect to that from the stable constituent phases is referred to as, by convention, the energy above the hull).

The phonon frequency spectrum of a theoretically predicted structure was used for examining its dynamic stability. The supercell method in the PHONOPY package ${ }^{50,51}$ was employed to perform the relevant frozen-phonon calculations based on harmonic approximation. The supercells of relaxed structures were used for phonon calculations. The stability criterion is that the amplitude of imaginary frequency is less than $-0.3 \mathrm{THz},{ }^{52,53}$ to accommodate acceptable numerical errors in phonon calculations. 
In our recent tests, $a b$ initio molecular dynamics (AIMD) can be carried out to describe the ionic transport behaviour at elevated temperatures to provide further insights via statistical processes, ${ }^{33,54-56}$ for which the diffusion coefficient $D$ and associated ionic conductivity $\sigma$ at any temperature can be estimated. In order to ensure a manageable AIMD analysis, simulation runs were performed on supercells of $\mathrm{Na}_{4(1-x)} \mathrm{Li}_{x} \mathrm{~A}_{a} \mathrm{X}_{b}$ with a time step of 2 fs in the NVT ensembles together with a Nosé-Hoover thermostat. Each AIMD run lasted for 80 ps after a preequilibrium run of $10 \mathrm{ps}$. In order to shorten the simulation time, elevated temperatures of 900 to $1300 \mathrm{~K}$ were employed to accelerate the ion hopping process (details of AIMD simulation are presented in $\mathrm{S} 2$ of the $\mathrm{ESI} \dagger$ ).

The Alloy-Theoretic Automated Toolkit (ATAT) ${ }^{57,58}$ is based on the method of cluster expansion, which is a powerful tool to establish phase equilibria of interest through minimization of the formation energies of variable compositions using firstprinciples calculations. A cluster expansion is considered to be converged when all the following conditions are satisfied: (a) all ground states are correctly reproduced, (b) no other new ground states are predicted, and (c) the cross-validation score is typically less than $0.025 \mathrm{eV}$. Therefore, energies predicted from the cluster expansion as a function of composition for each structure are generated. On the basis of the ground states for each composition, a convex hull is created to describe the phase equilibrium.

According to the low-energy states on the minimal edge of the convex hull, the average electrochemical potential $\bar{V}_{\overrightarrow{\mathrm{AB}}}$, for the transition between state $\mathrm{A}\left(\mathrm{Na}_{x} \Pi\right)$ and state $\mathrm{B}\left(\mathrm{Na}_{x+\Delta x} \Pi\right)$, with reference to electrochemical potential $v s . \mathrm{Na} / \mathrm{Na}^{+}$related to total energies $\left(E_{\mathrm{t}}\right)$ can be calculated by:

$$
\bar{V}_{\overrightarrow{\mathrm{AB}}}=-1 / z\left\{\left[E_{\mathrm{t}}\left(\mathrm{Na}_{x+\Delta x} \Pi\right)-E_{\mathrm{t}}\left(\mathrm{Na}_{x} \Pi\right)\right] / \Delta x-E_{\mathrm{t}}(\mathrm{Na})\right\}
$$

where $x$ is the number of $\mathrm{Na}$ in the formula unit of $\mathrm{Na}_{x} \prod$, charge value $z=1$ for $\mathrm{Na}^{+}, \Delta x$ is the change in the number of $\mathrm{Na}$ atoms, and $\Pi$ refers to the collection of other constituents. Again, energetically stable constituent phase structures for each compound are identified from the USPEX global search.

Overall, theoretical formulation for a competitive solid electrolyte involves phase stability, electrochemical stability against electrodes, ionic conductivity and electrochemical potential, as well as energy band structures. The phase stability aspect of modelling covers the stable and metastable structures for each composition (USPEX and PHONOPY), phase stability with respect to stable constituent phases (USPEX and PHONOPY), phase equilibria with respect to compositional change (ATAT), and potential reactions at interfaces, e.g. those with electrodes. Modelling of functional performance includes ionic conductivity (AIMD) and electrochemical potentials associated with electrolyte compositions and structures (eqn (2)).

A summary of methods as an integrated materials genome approach for the current work is presented in Fig. 1. A potential stable phase for each given composition can be identified, when it is energetically and dynamically stable, together with a negative energy above the hull to account for global equilibration. An allowance of $25 \mathrm{meV}$ per atom can be considered for the formation energy at $0 \mathrm{~K}$ to accommodate thermal fluctuation at standard room temperature $(298 \mathrm{~K}) .^{\mathbf{1 9 , 5 9 , 6 0}}$

The compositional dependence of phase stability, which is typically involved at interfaces between any two terminal compositions, can be readily simulated with the ATAT code, which results in a convex hull of formation energies, thus

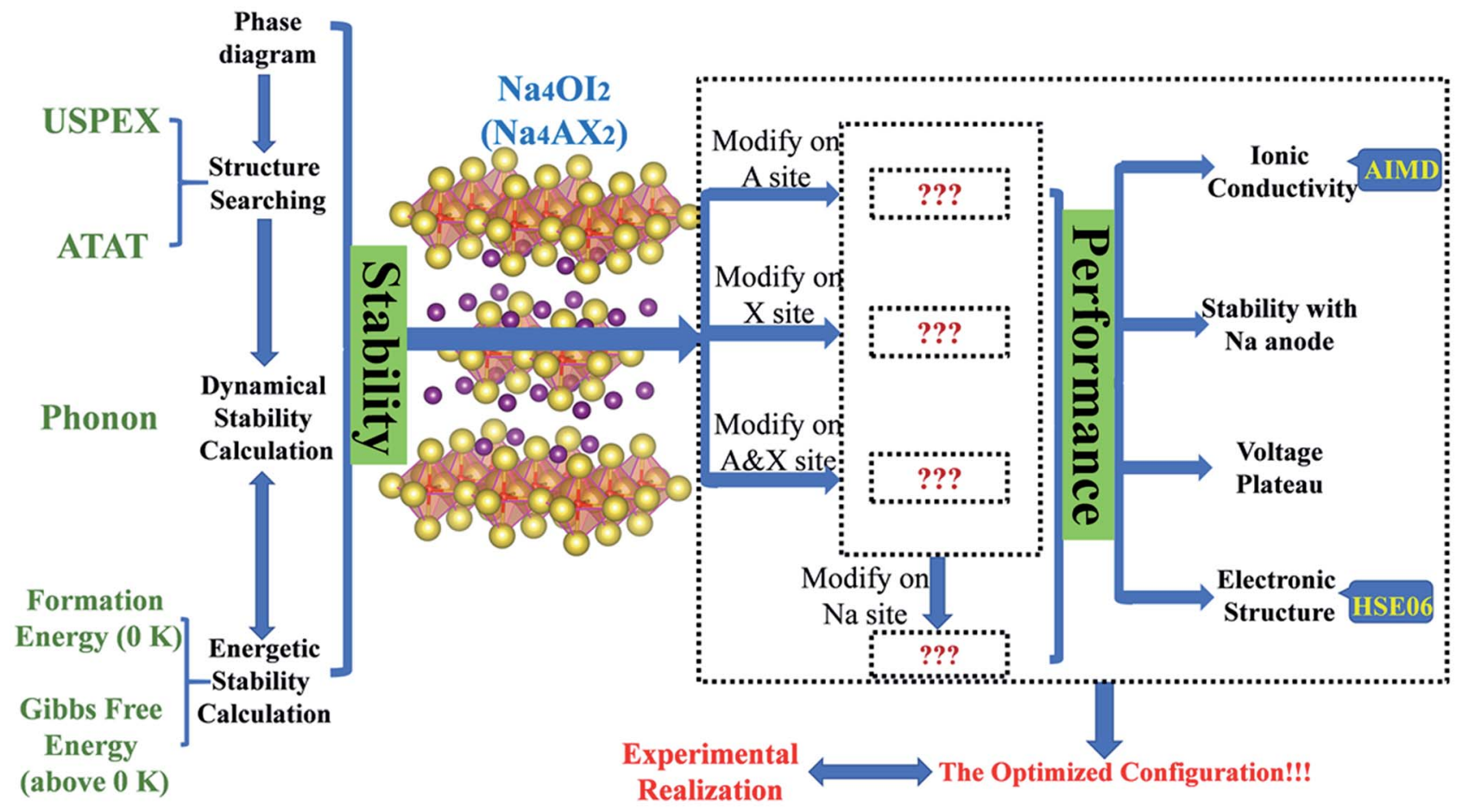

Fig. 1 Flow chart for the materials genome approach. 
leading to identification of thermodynamically stable phases between the stable phases of the terminal substances. Application of a PHONOPY simulation to thermodynamically stable structures leads to assessment of dynamical stability and phonon entropy as a major contribution to Gibbs free energy. ${ }^{7,16,18,33,54,61}$

\section{Discussion}

\section{The pristine $\mathrm{Na}_{4} \mathrm{OI}_{2}$ phase stability}

The $\mathrm{Na}_{4} \mathrm{OI}_{2}$ compound was synthesized through a solid-state reaction at about $350{ }^{\circ} \mathrm{C}$ previously. ${ }^{29}$ Let us examine the structural stability of the $\mathrm{Na}_{4} \mathrm{OI}_{2}$ configuration using USPEX as a materials genome tool based on global energy minimization at $0 \mathrm{~K}$, which identifies the most stable structure for the $\mathrm{Na}_{4} \mathrm{OI}_{2}$ composition, as shown in Fig. 2(a). The stable $\mathrm{Na}_{4} \mathrm{OI}_{2}$ phase contains layers of $\mathrm{Na}_{6} \mathrm{O}^{4+}$ octahedral units, which are basic units in a cubic anti-perovskite phase such as $\mathrm{Na}_{3} \mathrm{OCl}$ with the $P M \overline{3} M(221)$ space group. The $\mathrm{I}^{-}$anions sitting between the octahedral layers help in binding with $\mathrm{Na}^{+}$cations in between, thus leading to a tetragonal lattice with the space group of $I \overline{4} M M M(139)$. Such a phase is of the same layered characteristics of the Ruddlesden-Popper phase, ${ }^{\mathbf{6 2}-64}$ albeit being based on anti-perovskite structural units instead of perovskite units. It is thus termed as an anti-Ruddlesden-Popper (ARP) phase in this work. Also, PHONOPY calculations, within the quasi-harmonic approximation, show that the $\mathrm{Na}_{4} \mathrm{OI}_{2}$ phase (126 atoms) is dynamically or mechanically stable, with no states associated with imaginary frequencies, Fig. 2(b).

In addition, the ground state $\mathrm{Na}_{4} \mathrm{OI}_{2}$ phase is stable with respect to constituent binary phases $\mathrm{Na}_{2} \mathrm{O}$ and $\mathrm{NaI}$ at $0 \mathrm{~K}$, with the pseudo-binary phase diagram being shown in Fig. 1(c). Temperature dependence of phase equilibria can be derived with the consideration of the phonon entropy in Gibbs energies:

$$
\Delta G_{\mathrm{Na}_{4} \mathrm{OI}_{2}}=G_{\mathrm{Na}_{4} \mathrm{OI}_{2}}-G_{\mathrm{Na}_{2} \mathrm{O}}-2 G_{\mathrm{NaI}}
$$

(a)

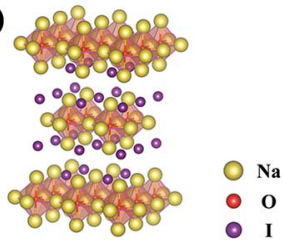

(c)

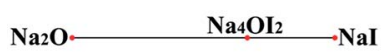

(b)

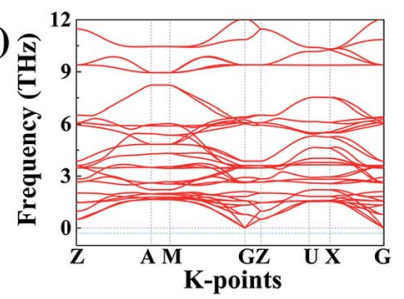

(d)

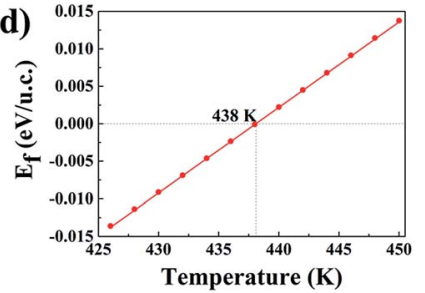

Fig. 2 (a) The pristine stable phase from USPEX energy minimization in $\mathrm{Na}_{4} \mathrm{Ol}_{2}$. (b) Calculated phonon band structures for pristine $\mathrm{Na}_{4} \mathrm{OI}_{2}$. (c) Phase diagram showing $\mathrm{Na}_{4} \mathrm{Ol}_{2}$ being in equilibrium with constituent phases at $0 \mathrm{~K}$. (d) Free energy of formation (eV per unit-cell) above the hull for the $\mathrm{Na}_{4} \mathrm{Ol}_{2}$ phase. where both the ground-state stable constituent phases, $\mathrm{Na}_{2} \mathrm{O}$ and NaI, are also dynamically stable. It is found that the constituent phases are more stable at temperatures higher than $438 \mathrm{~K}\left(165^{\circ} \mathrm{C}\right)$, Fig. $2(\mathrm{~d})$. This suggests that phase equilibrium can only be reached at moderate temperatures below $165{ }^{\circ} \mathrm{C}$, though such moderately low temperature would limit longdistance diffusion and thus slows the equilibration process. This in turn is consistent with the fact that it was rather difficult to eliminate constituent phases by sintering at a higher temperature $\left(350{ }^{\circ} \mathrm{C}\right){ }^{29}$

Since the pristine $\mathrm{Na}_{4} \mathrm{OI}_{2}$ is known to be a rather poor conductor for $\mathrm{Na}^{+}$ions, it is necessary to tune its materials chemistry in order to meet requests for competitive SSEs. This involves tailoring materials chemistry over every sublattice site based on $\mathrm{M}_{4} \mathrm{AX}_{2}(\mathrm{M}=$ alkali metal, $\mathrm{A}=$ chalcogen, and $\mathrm{X}=$ halogen).

\section{Iso-valent substitution in $\mathrm{Na}_{4} \mathrm{AX}_{2}$}

Stable and metastable structures for each possible $\mathrm{Na}_{4} \mathrm{AX}_{2}$ chemical component are identified by USPEX through global energy minimization. The energy of formation of each compound is defined against its stable constituent phases (i.e. the energies above the hull), e.g. $\mathrm{Na}_{2} \mathrm{O}, \mathrm{Na}_{2} \mathrm{~S}, \mathrm{NaCl}$ and $\mathrm{NaI}$. The outcome is summarized in Fig. 3.

Iso-valent substitution of $\mathrm{I}^{-}$on the halogen $\mathrm{X}$ site with a smaller halogen species $\mathrm{Cl}^{-}$results in stable compounds with respect to the constituent binary phases. While complete replacement of $\mathrm{I}^{-}$by $\mathrm{Cl}^{-}$still keeps the same lattice symmetry as the stable structure, $\mathrm{Na}_{4} \mathrm{OCl}_{2} \_139$ (numerable refers to space group number 139), partial substitution of I by Cl leads to stable and metastable compounds with different space groups, $\mathrm{Na}_{4}$ OICl_63 and $\mathrm{Na}_{4} \mathrm{OICl} \_129$. The corresponding formation energies are $-0.0098,-0.0114$ and $-0.004 \mathrm{eV}$ per atom ( $v s$. formation energy for $\mathrm{Na}_{4} \mathrm{OI}_{2}-0.027 \mathrm{eV}$ per atom), so that they are more stable than the constituent binary phases at $0 \mathrm{~K}$ (in terms of energies: $\mathrm{Na}_{4} \mathrm{OCl}_{2}<\mathrm{Na}_{2} \mathrm{O}+2 \mathrm{NaCl}, \mathrm{Na}_{4} \mathrm{OICl}<\mathrm{Na}_{2} \mathrm{O}+$ $\mathrm{NaI}+\mathrm{NaCl})$.

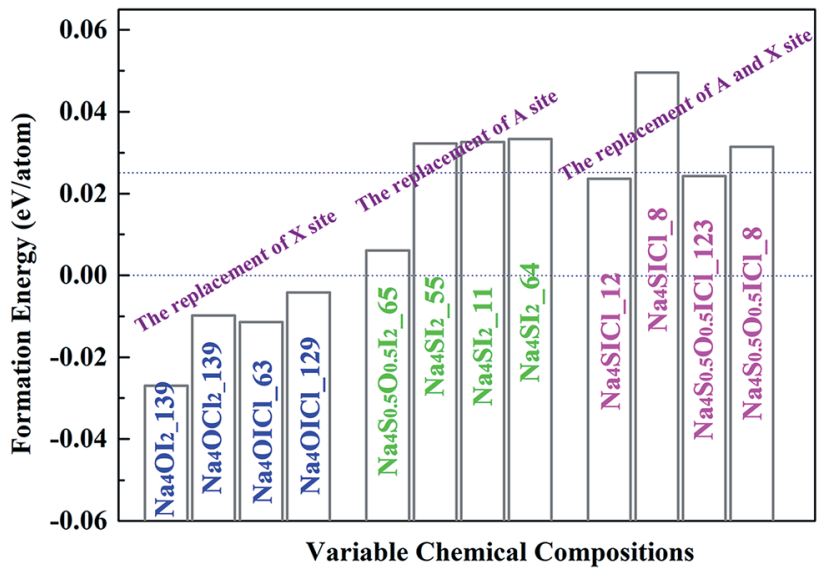

Fig. 3 Formation energies for $\mathrm{Na}_{4} \mathrm{AX}_{2}$ based alloys with respect to stable constituent phases, i.e. the energies above the hull. Thermal activation at standard room temperature $(298 \mathrm{~K})$ is indicated $(0.025 \mathrm{eV}$ per atom). 
On the chalcogen A site, replacement of $\mathrm{O}$ by $\mathrm{S}$ results in $\mathrm{Na}_{4} \mathrm{~S}_{0.5} \mathrm{O}_{0.5} \mathrm{I}_{2} \_65, \mathrm{Na}_{4} \mathrm{SI}_{2 \_} 55, \mathrm{Na}_{4} \mathrm{SI}_{2} \_11$ and $\mathrm{Na}_{4} \mathrm{SI}_{2 \_}$64. The corresponding formation energies for them are $0.006,0.0323$, 0.0326 and $0.0334 \mathrm{eV}$ per atom above the hull, which are only slightly less stable than their constituent phases.

In the case of iso-valent substitution on both the chalcogen (A) and the halogen (X) sites, four energetically favoured structures emerge as $\mathrm{Na}_{4} \mathrm{SICl} \_12$ (0.024 eV per atom), $\mathrm{Na}_{4} \mathrm{SICl} \_8$ (0.050 eV per atom), $\mathrm{Na}_{4} \mathrm{~S}_{0.5} \mathrm{O}_{0.5} \mathrm{ICl} \_123(0.024 \mathrm{eV}$ per atom), and $\mathrm{Na}_{4} \mathrm{~S}_{0.5} \mathrm{O}_{0.5} \mathrm{ICl} \_8$ (0.031 eV per atom). Table 1 summarizes the USPEX searched structures, covering space groups and lattice parameters. The emboldened phases are stable with respect to constituent phases, and those starred are also considered as potential candidates for practical synthesis, with formation energies above the hull not exceeding the $0.025 \mathrm{eV}$ per atom marker.

\section{The chosen phase from $\mathrm{Na}_{4} \mathrm{AX}_{2}$}

Among the three energetically favoured structures of $\mathrm{Na}_{4} \mathrm{OCl}_{2} \_139, \mathrm{Na}_{4} \mathrm{OICl} \_63$ and $\mathrm{Na}_{4} \mathrm{OICl} \_129$, the $\mathrm{Na}_{4} \mathrm{OICl} \_63$ phase is the most stable with respect to stable constituent phases, with the halogen sites equally shared by $\mathrm{Cl}^{-}$and $\mathrm{I}^{-}$. The phase is base centred, with the CMCM space group symmetry (number 63), Fig. 4(a), which is characteristic of the zigzag layers of $\mathrm{Na}_{6} \mathrm{O}^{4+}$ units, the basic octahedra in the layers as a framework of the $\mathrm{Na}_{4} \mathrm{OI}_{2} 139$ phase. While rows of $\mathrm{I}^{-}$anions appear along the hollow space within each zigzag layer of octahedra, rows of $\mathrm{Cl}^{-}$anions are present between the layers. Of the two types of halogen anions, the smaller but stronger $\mathrm{Cl}^{-}$ anions largely contribute to bind the zigzag layers via electrostatic attraction with Na cations, while the weaker $\mathrm{I}^{-}$anions stay in the hollow space to help brace up the layered structure via electrostatic repelling the neighbouring rows of $\mathrm{Cl}^{-}$anions. Therefore, it is the combined geometric and electrostatic factors that lead to dramatic reconstruction of initially flat sheets of octahedra, the basic units in anti-perovskites, into matching zigzag layers, Fig. 4(a).

The ground state stable phase of $\mathrm{Na}_{4} \mathrm{OICl}$ (space group number 63) is also confirmed to be dynamically stable owing to the lack of phonon states associated with imaginary (a)

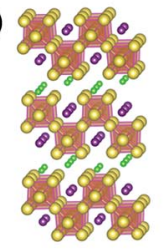

(c)

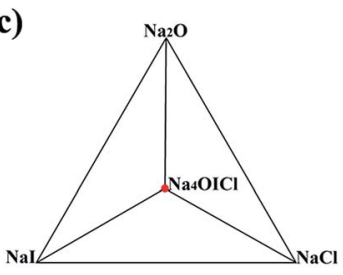

(b)

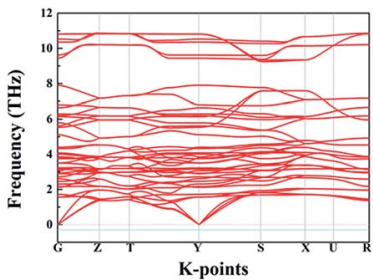

(d)

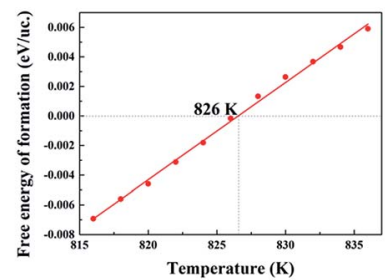

Fig. 4 (a) USPEX identified $\mathrm{Na}_{4} \mathrm{OICl} 63$ with the lowest energy. (b) Calculated phonon band structure for $\mathrm{Na}_{4} \mathrm{OICl}$ 63. (c) Phase diagrams for $\mathrm{Na}_{4} \mathrm{OICl} 63$ at $0 \mathrm{~K}$ with its constituent phases. (d) Free energy of formation above the hull for $\mathrm{Na}_{4} \mathrm{OICl} 63$.

frequencies, as shown by the phonon band structure from its 2 $\times 2 \times 1$ supercell containing 28 atoms, Fig. 4(b). The zigzag structural framework containing alternating rows of $\mathrm{I}^{-}$and $\mathrm{Cl}^{-}$ anions is therefore dynamically stable as well. It is well recognized that dynamically stable phases, even those with energy slightly above the hull, tend to exist in nature.

The ground state phase diagram for the formation of $\mathrm{Na}_{4}-$ OICl_63 is shown in Fig. 4(c), which is in equilibrium with the three constituent phases $\mathrm{Na}_{2} \mathrm{O}, \mathrm{NaI}$ and $\mathrm{NaCl}$ at $0 \mathrm{~K}$. The free energy above the hull, within the quasi-harmonic approximation to consider the phonon entropy, can therefore be defined as:

$$
\Delta G_{\mathrm{Na}_{4} \mathrm{OICl}}=G_{\mathrm{Na}_{4} \mathrm{OICl}}-G_{\mathrm{Na}_{2} \mathrm{O}}-G_{\mathrm{NaI}}-G_{\mathrm{NaCl}}
$$

It follows that $\Delta G_{\mathrm{Na}_{4} \mathrm{OICl}}$ turns out to be positive above a critical temperature of $826 \mathrm{~K}$, Fig. 4(d), so that this phase is stable within a much wider temperature range than the pristine phase of $\mathrm{Na}_{4} \mathrm{OI}_{2} \_139$ (826 K vs. $438 \mathrm{~K}$ ). Such an outstanding combination of energetic and dynamical stability indicates it would be much easier for its practical delivery in a wide

Table 1 Lattice parameters and symmetry groups of various configurations from USPEX global searching

\begin{tabular}{|c|c|c|c|c|c|c|c|}
\hline Configuration & $A$ & $B$ & $c(\AA)$ & $\alpha$ & $\beta$ & $\gamma\left({ }^{\circ}\right)$ & Symmetry \\
\hline $\mathrm{Na}_{4} \mathrm{OI}_{2} \_139$ & 4.6714 & 4.6714 & 16.1014 & 90 & 90 & 90 & $I \overline{4} M M M(139)$ \\
\hline $\mathrm{Na}_{4} \mathrm{OCl}_{2} \_139$ & 4.4066 & 4.4066 & 14.2356 & 90 & 90 & 90 & $I \overline{4} M M M(139)$ \\
\hline $\mathrm{Na}_{4} \mathrm{OICl} \_63$ & 4.5745 & 19.7556 & 6.823 & 90 & 90 & 90 & $\mathrm{CMCM}(63)$ \\
\hline $\mathrm{Na}_{4} \mathrm{OICl} \_129$ & 4.517 & 4.517 & 15.0419 & 90 & 90 & 90 & $P \overline{4} N M M(129)$ \\
\hline $\mathrm{Na}_{4} \mathrm{~S}_{0.5} \mathrm{O}_{0.5} \mathrm{I}_{2 \_} 65$ & 16.3097 & 6.9654 & 9.9591 & 90 & 90 & 90 & $C M M M(65)$ \\
\hline $\mathrm{Na}_{4} \mathrm{SI}_{2 \_} 11$ & 7.0334 & 4.5365 & 13.6175 & 90 & 88.1004 & 90 & $P 2 \overline{1} M(11)$ \\
\hline $\mathrm{Na}_{4} \mathrm{SI}_{2} \_55$ & 7.6833 & 13.2245 & 4.4076 & 90 & 90 & 90 & $P B A M(65)$ \\
\hline $\mathrm{Na}_{4} \mathrm{SI}_{2 \_} 64$ & 7.4196 & 16.4631 & 7.5097 & 90 & 90 & 90 & $C M C A(64)$ \\
\hline $\mathrm{Na}_{4} \mathrm{SICl} \_8$ & 25.2976 & 4.5048 & 7.356 & 90 & 88.0375 & 90 & $C M(8)$ \\
\hline $\mathrm{Na}_{4} \mathrm{SICl} \_12$ & 24.1735 & 4.3758 & 7.7573 & 90 & 99.3575 & 90 & $C \overline{2} M(12)$ \\
\hline $\mathrm{Na}_{4} \mathrm{~S}_{0.5} \mathrm{O}_{0.5} \mathrm{ICl} \_8$ & 21.4945 & 4.68504 & 7.096 & 90 & 90.0102 & 90 & $C M(8)$ \\
\hline $\mathrm{Na}_{4} \mathrm{~S}_{0.5} \mathrm{O}_{0.5} \mathrm{ICl} 123$ & 4.7755 & 4.7755 & 15.2731 & 90 & 90 & 90 & $P \overline{4} M M M(123)$ \\
\hline
\end{tabular}


temperature window for processing, e.g. through mechanical alloying followed by power sintering. ${ }^{35}$

However, the other two energetically stable compounds, $\mathrm{Na}_{4} \mathrm{OCl}_{2}(I \overline{4} M M M(139))$ and $\mathrm{Na}_{4} \mathrm{OICl}(P \overline{4} N M M(129))$, are not dynamically stable, as exhibited in Fig. S1(a) and (b), $\dagger$ respectively. The phonon band structures for each of them have bands associated below the $-0.3 \mathrm{THz}$ threshold, Fig. $\mathrm{S} 1\left(\mathrm{a}^{\prime}\right)$ and $\left(\mathrm{b}^{\prime}\right) . \dagger$

\section{Optimization on the A site of $\mathrm{Na}_{4} \mathrm{AX}_{2}$}

USPEX searching results in four potential structural configurations, i.e. $\mathrm{Na}_{4} \mathrm{~S}_{0.5} \mathrm{O}_{0.5} \mathrm{I}_{2} \_65, \mathrm{Na}_{4} \mathrm{SI}_{2} \_55, \mathrm{Na}_{4} \mathrm{SI}_{2 \_} 11$ and $\mathrm{Na}_{4} \mathrm{SI}_{2} \_64$. The most stable one, $\mathrm{Na}_{4} \mathrm{~S}_{0.5} \mathrm{O}_{0.5} \mathrm{I}_{2} 65$ with the $C M M M$ symmetry, has a negligible energy above the hull $(0.006 \mathrm{eV})$ at $0 \mathrm{~K}$. This energetically favoured phase is characterized with planar layers made of alternating $\mathrm{Na}_{6} \mathrm{O}^{4+}$ and $\mathrm{Na}_{6} \mathrm{~S}^{4+}$ octahedra. Such alternating arrangement of chalcogen octahedra is characteristic of cubic double anti-perovskite phases, ${ }^{33}$ and we therefore can classify this phase as a double anti-RuddlesdenPopper phase (DARP) based on interlocking $\mathrm{Na}_{4} \mathrm{OI}_{2 \_} 139$ and $\mathrm{Na}_{4} \mathrm{SI}_{2} \_139$ APR units, Fig. 5(a).

Besides, the $\mathrm{Na}_{4} \mathrm{~S}_{0.5} \mathrm{O}_{0.5} \mathrm{I}_{2}$ 65 (112 atoms) is also dynamically stable without any phonon bands related to imaginary frequencies, Fig. 5(b). The free energy above the hull for $\mathrm{Na}_{4} \mathrm{~S}_{0.5} \mathrm{O}_{0.5} \mathrm{I}_{2} \_5$ is,

$$
\Delta G_{\mathrm{Na}_{4} \mathrm{~S}_{0.5} \mathrm{O}_{0.5} \mathrm{I}_{2}}=G_{\mathrm{Na}_{4} \mathrm{~S}_{0.5} \mathrm{O}_{0.5} \mathrm{I}_{2}}-0.5 G_{\mathrm{Na}_{2} \mathrm{~S}}-0.5 G_{\mathrm{Na}_{2} \mathrm{O}}-2 G_{\mathrm{NaI}}
$$

As is shown in Fig. 5(d), $\Delta G_{\mathrm{Na}_{4} \mathrm{~S}_{0.5} \mathrm{O}_{0.5} \mathrm{I}_{2}}$ becomes negative above $140 \mathrm{~K}\left(-133{ }^{\circ} \mathrm{C}\right)$, indicating that this phase is energetically favoured over any thermal environment of practical interest, e.g. well over room temperature. This is desirable for practical synthesis of the compound so that it can be processed over a very wide temperature range without worrying about its decomposition into constituent binary phases.

The other three candidates, $\mathrm{Na}_{4} \mathrm{SI}_{2} \_55, \mathrm{Na}_{4} \mathrm{SI}_{2} \_11$ and $\mathrm{Na}_{4} \mathrm{SI}_{2} \_64$, are slightly less competitive energetically with (a)

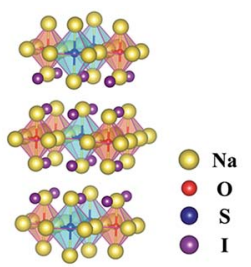

(c)

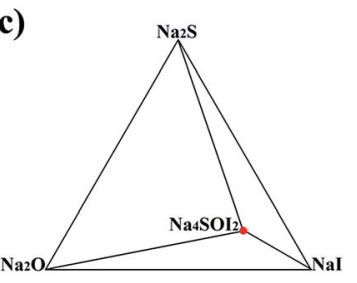

(b)

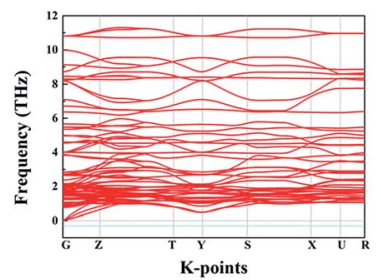

(d)

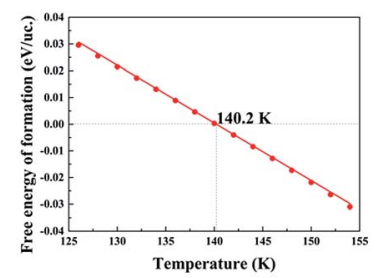

Fig. 5 (a) The stable structure $\mathrm{Na}_{4} \mathrm{~S}_{0.5} \mathrm{O}_{0.5} \mathrm{I}_{2} 65$ from USPEX searching. (b) Calculated phonon band structures for $\mathrm{Na}_{4} \mathrm{~S}_{0.5} \mathrm{O}_{0.5} \mathrm{I}_{2} \_6$. (c) Phase equilibrium between $\mathrm{Na}_{4} \mathrm{~S}_{0.5} \mathrm{O}_{0.5} \mathrm{I}_{2}-65$ and constituent phases at $140.2 \mathrm{~K}$. (d) Free energy of formation above the hull for the $\mathrm{Na}_{4} \mathrm{~S}_{0.5} \mathrm{O}_{0.5} \mathrm{I}_{2}-65$ compound, showing it being stable at any practical thermal ambient $\left(>-130^{\circ} \mathrm{C}\right)$. energies above the hull being close to $0.025 \mathrm{eV}$ (0.0323, 0.0326 and $0.0334 \mathrm{eV}$ correspondingly). The layered structures are maintained with the first two being also dynamically stable, as is evidenced in Fig. S2(a)-(c). $\dagger$

In the case of iso-valent substitution of both the chalcogen and halogen sites, USPEX searching results in four structural configurations, $\quad \mathrm{Na}_{4} \mathrm{SICl} \_12, \quad \mathrm{Na}_{4} \mathrm{SICl} \_8, \quad \mathrm{Na}_{4} \mathrm{~S}_{0.5} \mathrm{O}_{0.5} \mathrm{ICl}$ 123, $\mathrm{Na}_{4} \mathrm{~S}_{0.5} \mathrm{O}_{0.5} \mathrm{ICl} \_8$, as exhibited in Fig. S3. $\dagger$ It is found that the latter two phases, $\mathrm{Na}_{4} \mathrm{~S}_{0.5} \mathrm{O}_{0.5} \mathrm{ICl} \_123$ and $\mathrm{Na}_{4} \mathrm{~S}_{0.5} \mathrm{O}_{0.5} \mathrm{ICl} \_8$, are dynamically unstable.

Table $\mathrm{S} 1 \dagger$ summarizes the overall finding on iso-valent substitution in the $\mathrm{Na}_{4} \mathrm{OI}_{2}$ phase. In addition to the pristine $\mathrm{Na}_{4} \mathrm{SI}_{2} \_139$ phase, we have thus identified $\mathrm{Na}_{4} \mathrm{OICl} \_63$ and $\mathrm{Na}_{4} \mathrm{~S}_{0.5} \mathrm{O}_{0.5} \mathrm{I}_{2} 65$ (DARP) as most promising structures with greater stability.

\section{Iso-valent doping on the $\mathrm{Na}$ site of $\mathrm{Na}_{4} \mathrm{AX}_{2}$}

Iso-valent replacement of $\mathrm{Na}$ with $\mathrm{Li}$ has also been investigated, on the basis of the DARP $\mathrm{Na}_{4} \mathrm{~S}_{0.5} \mathrm{O}_{0.5} \mathrm{I}_{2}$ phase, since firstly it has the widest temperature window for both energetic and dynamical stability, and secondly $\mathrm{S}$ substitution of $\mathrm{O}$ is expected to soften the lattice to induce improved ionic conductivity. ${ }^{18,35}$ ATAT searching outcome for the stable configurations is represented as an convex hull, through the combination of DFT with cluster expansion simulation over $\mathrm{Na}_{4(1-x)} \mathrm{Li}_{x} \mathrm{~S}_{0.5} \mathrm{O}_{0.5} \mathrm{I}_{2}(0 \leq x \leq 1)$. As is shown in Fig. 6(a), the most stable structural configuration is based on substitution of a quarter of the $\mathrm{Na}$ site by Li. On the basis of chemical potential minimization, the stable phases are those sitting over the minimal common tangents between any two points on the bottom edge of the convex hull. Consequently, Fig. 6(a) suggests unlimited potential for mixing $\mathrm{Na}_{4} \mathrm{~S}_{0.5} \mathrm{O}_{0.5} \mathrm{I}_{2}$ with $\mathrm{Li}_{4} \mathrm{~S}_{0.5} \mathrm{O}_{0.5} \mathrm{I}_{2}$ into alloys. Substitution of a quarter of the $\mathrm{Na}$ sites leads to the structure shown in Fig. 6(b), which is also dynamically stable owing to the lack of phonon bands associated with imaginary frequencies, as shown in Fig. 6(c), a phonon band structure from its $2 \times 1 \times 2$ supercell containing 112 atoms.

\section{Ionic conductivity}

Ionic conductivity is determined by the diffusion of alkali ions. Fig. 7 shows the plot of the Arrhenius relationships of potential electrolytes of interest, with a vacancy of $\mathrm{Na}^{+}$being considered for every 32 alkali ions, similar to the vacancy ionic transportation mechanism illustrated in the anti-perovskite system. 16,33,65 Data derived from Fig. 7 are summarized in Table 2. For the pristine $\mathrm{Na}_{4} \mathrm{OI}_{2}$ phase, the activation barrier of $E_{\mathrm{a}}=0.37 \mathrm{eV}$ is largely consistent with the result of $0.3 \mathrm{eV}$ from LST/QST simulation using CASTEP. ${ }^{32}$ The corresponding $\mathrm{Na}^{+}$ conductivity $(\sigma)$ is only $5.89 \times 10^{-2} \mathrm{mS} \mathrm{cm}^{-1}$ at room temperature $(298 \mathrm{~K})$. Introducing $\mathrm{Cl}^{-}$to share the halogen site with $\mathrm{I}^{-}$ leads to an even bigger activation barrier for $\mathrm{Na}^{+}$diffusion in $\mathrm{Na}_{4} \mathrm{OICl}(0.44 \mathrm{eV})$, together with poorer $\mathrm{Na}^{+}$conductivity as low as $8.79 \times 10^{-4} \mathrm{mS} \mathrm{cm}^{-1}$ at room temperature. This is understandable, considering that stronger electrostatic attraction to the interlayer $\mathrm{Cl}^{-}$anions tends to keep $\mathrm{Na}^{+}$from hopping 
(a)

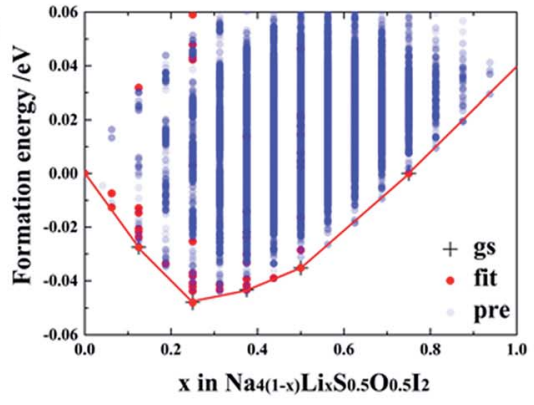

(b)

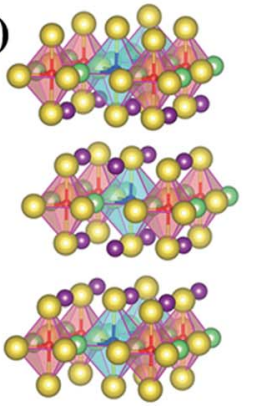

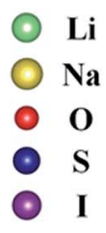

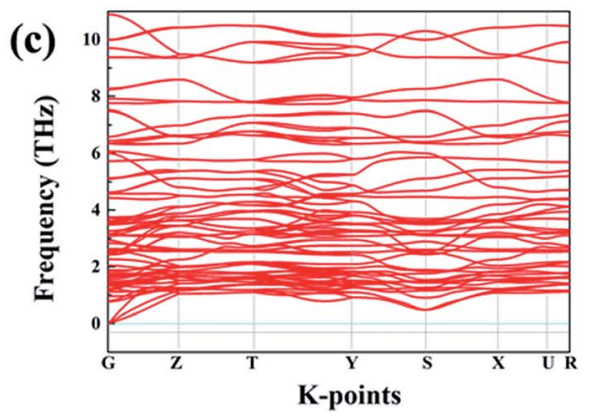

Fig. 6 (a) The convex hull for $\mathrm{Na}_{4(1-x)} \mathrm{Li}_{x} \mathrm{~S}_{0.5} \mathrm{O}_{0.5} \mathrm{I}_{2}(\mathrm{O} \leq x \leq 1)$ through ATAT simulation. (b) Stable structure for $\mathrm{Na}_{3} \mathrm{LiSO}_{.5} \mathrm{O}_{0.5} \mathrm{I}_{2}-65$ corresponding to minimal energy. (c) Calculated phonon band structures for $\mathrm{Na}_{3} \mathrm{LiS}_{0.5} \mathrm{O}_{0.5} \mathrm{I}_{2}$.

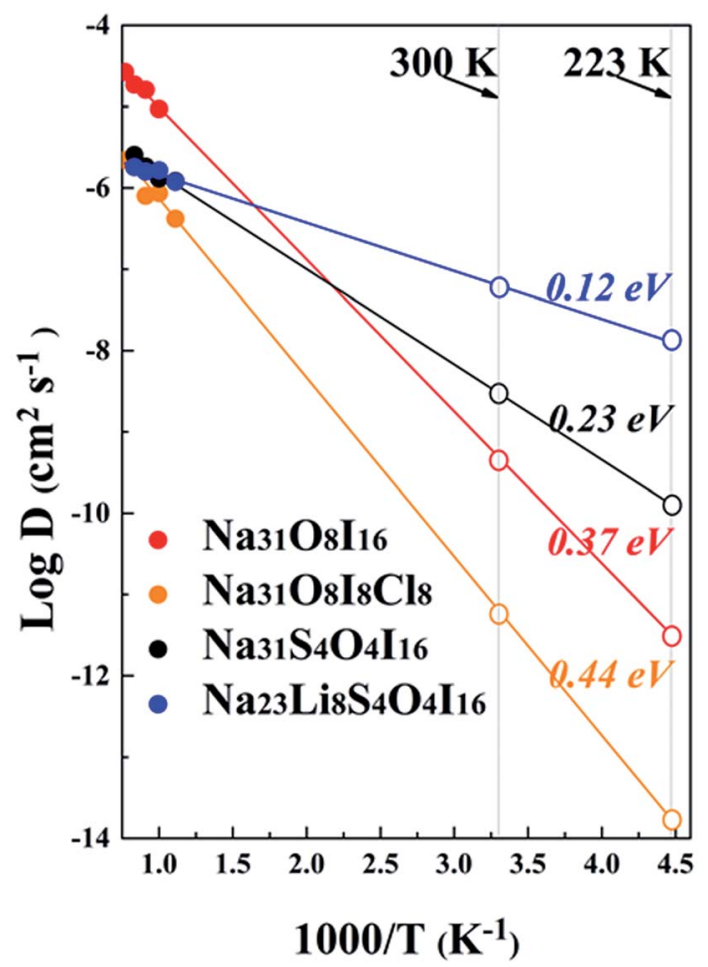

Fig. 7 Diffusion coefficients for sodium ions from AIMD simulation. The extrapolated $D$ values at room temperature and $-50{ }^{\circ} \mathrm{C}$ are presented by open patterns on the right.

(layers of the zigzag structural framework are closer to each other, thus hindering the migration of $\mathrm{Na}^{+}$ions). On the other hand, with $50 \% \mathrm{~S}$ substitution of the $\mathrm{O}$ site in $\mathrm{Na}_{4} \mathrm{OI}_{2}$, the activation barrier in $\mathrm{Na}_{4} \mathrm{~S}_{0.5} \mathrm{O}_{0.5} \mathrm{I}_{2-} 65$ (i.e. $\mathrm{Na}_{31} \mathrm{~S}_{4} \mathrm{O}_{4} \mathrm{I}_{16}$ ) is reduced significantly down to $0.23 \mathrm{eV}$, with $\mathrm{Na}^{+}$ion conductivity increased over two order up to $0.347 \mathrm{mS} \mathrm{cm} \mathrm{cm}^{-1}$ at room temperature. This is comparable to the best reported data for solid sodium ion conductors such as $\mathrm{Na}_{11} \mathrm{Sn}_{2} \mathrm{PS}_{12}\left(E_{\mathrm{a}}=0.25 \mathrm{eV}\right.$, $\sigma=1.4 \mathrm{mS} \mathrm{cm}{ }^{-1}$ at $\left.300 \mathrm{~K}\right) .{ }^{20}$ Such significant improvement of ionic conductivity through substitution of $\mathrm{O}$ with $\mathrm{S}$ is consistent with recent theoretical prediction and experimental confirmation that the reduced electrostatic attraction between $\mathrm{S}$ and alkali ions leads to lattice softening. ${ }^{18,35}$

It is amazing to find that in the case of the hybrid electrolyte $\mathrm{Na}_{3} \mathrm{LiS}_{0.5} \mathrm{O}_{0.5} \mathrm{I}_{2}$, the activation barrier in $\mathrm{Na}_{23} \mathrm{Li}_{8} \mathrm{~S}_{4} \mathrm{O}_{4} \mathrm{I}_{16}$ is reduced by a further half down to $0.12 \mathrm{eV}$, together with a remarkable $\mathrm{Na}^{+}$conductivity of up to $6.3 \mathrm{mS} \mathrm{cm}^{-1}$ (4.5 times of that in $\mathrm{Na}_{11} \mathrm{Sn}_{2} \mathrm{PS}_{12}$ ). The very low activation energy also helps safeguard an ionic conductivity of $1.31 \mathrm{mS} \mathrm{cm}^{-1}$ at $-50{ }^{\circ} \mathrm{C}$, which is extremely useful for a promising SSE. Meanwhile, as shown in Fig. $\mathrm{S} 4, \uparrow$ the mean square displacements (MSDs) of anions, e.g. $\mathrm{S}^{-2}, \mathrm{O}^{-2}$, and $\mathrm{I}^{-}$, are minimal, suggesting that they are largely confined around equilibrium positions. On the other hand, $\mathrm{Li}^{+} / \mathrm{Na}^{+}$ions experience long distance transportation in a coordinated way, owing to the great energetic advantage of the stoichiometric composition.

The $\mathrm{Na}^{+}$ion trajectories for $\mathrm{Na}_{4} \mathrm{~S}_{0.5} \mathrm{O}_{0.5} \mathrm{I}_{2}$ and $\mathrm{Na}_{3} \mathrm{LiS}_{0.5} \mathrm{O}_{0.5} \mathrm{I}_{2}$ at $800 \mathrm{~K}$ are compared in Fig. 8. In the case of $\mathrm{Na}_{4} \mathrm{~S}_{0.5} \mathrm{O}_{0.5} \mathrm{I}_{2}$, the trajectory is still somewhat localized around $\mathrm{Na}_{6} \mathrm{O}^{4+}$ octahedral units. When $\mathrm{Li}^{+}$ions are introduced into the $\mathrm{Na}^{+}$sites, the longrange transportation of $\mathrm{Na}^{+}$over half of the unit cell can be observed. The co-existence of smaller $\mathrm{Li}^{+}$ions, therefore, induces knocking-on effects to promote the transportation of the bigger $\mathrm{Na}^{+}$ions. The overall $\mathrm{Na}^{+} / \mathrm{Li}^{+}$ion trajectories for $\mathrm{Na}_{3} \mathrm{LiS}_{0.5} \mathrm{O}_{0.5} \mathrm{I}_{2}$ are presented in Fig. $\mathrm{S} 5, \dagger$ where continuous two-

Table 2 Summary of data for ionic diffusion and conductivity of this work

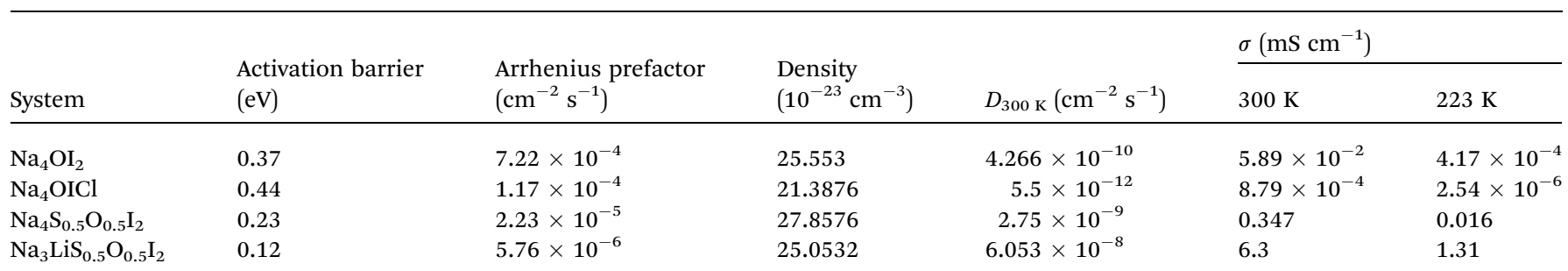


(a)

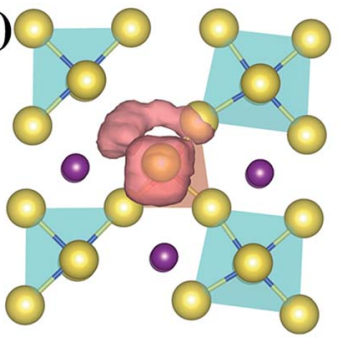

(a')

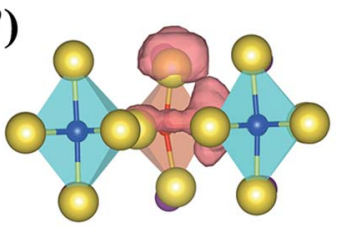

(b)

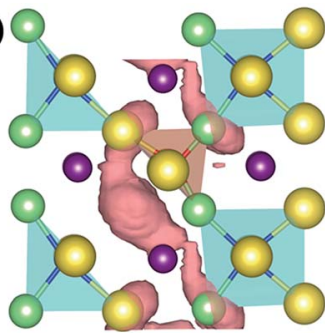

(b')

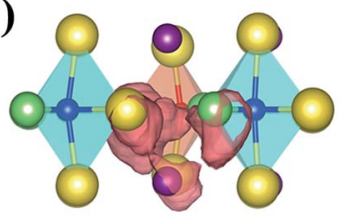

Fig. 8 Projections of diffusion trajectories of sodium ions from the top view for (a) $\mathrm{Na}_{31} \mathrm{~S}_{4} \mathrm{O}_{4} \mathrm{l}_{16}$ and (b) $\mathrm{Na}_{23} \mathrm{Li}_{8} \mathrm{~S}_{4} \mathrm{O}_{4} \mathrm{l}_{16}$ and the side view for $\left(a^{\prime}\right)$ $\mathrm{Na}_{31} \mathrm{~S}_{4} \mathrm{O}_{4} \mathrm{I}_{16}$ and $\left(b^{\prime}\right) \mathrm{Na}_{23} \mathrm{Li}_{8} \mathrm{~S}_{4} \mathrm{O}_{4} \mathrm{I}_{16}$, over a simulation time of 90 ps at $800 \mathrm{~K}$.

dimensional channels between the layered structural units are clearly revealed. The basic layered structural units are maintained over the AIMD process at such an elevated temperature, indicating high material stability together with high mobility of alkali ions. Such a theoretical observation is similar to the $\mathrm{Li}^{+}$ effect on $\mathrm{Mg}^{2+}$ in the hybrid $\mathrm{Li}^{+} / \mathrm{Mg}^{+}$cathode. ${ }^{7}$ Huang et al. ${ }^{66}$ and Du et al. ${ }^{67}$ reported that a tiny amount of $\mathrm{Li}^{+}$substitution of $\mathrm{Na}^{+}$ in sodium oxide cathodes $\mathrm{Na}_{x} \mathrm{TMO}_{2}$ led to significantly improved electrochemical kinetics and cycling performances, which may be attributed to the same reason as for enhanced $\mathrm{Na}^{+}$transportation.

\section{Electrochemical compatibility with the $\mathrm{Na}$ anode}

The interfacial stability between the optimized electrolyte and sodium anode can be investigated by AIMD simulation at elevated temperature, using a sandwich model of $\mathrm{Na} \mid \mathrm{Na}_{3}$ $\mathrm{LiS}_{0.5} \mathrm{O}_{0.5} \mathrm{I}_{2} \mid \mathrm{Na}$, as shown in Fig. S6(a). $\dagger$ It is shown that no interfacial reaction occurs after AIMD simulation for 90 ps well above the melting point of sodium (500 K), Fig. S6 (b). $\dagger$ Besides, the change in pair correlation functions (PCF) for O-Li, O-Na, $\mathrm{S}-\mathrm{Li}$ and $\mathrm{S}-\mathrm{Na}$ is shown in Fig. S7, $\dagger$ which demonstrates trivial changes over the simulation time. The $\mathrm{Na}_{3} \mathrm{LiS}_{0.5} \mathrm{O}_{0.5} \mathrm{I}_{2}$ compound is thermodynamically more stable than its constituent binary phases, i.e. $E\left(\mathrm{Na}_{3} \mathrm{LiS}_{0.5} \mathrm{O}_{0.5} \mathrm{I}_{2}\right)<E\left(0.5 \mathrm{Na}_{2} \mathrm{O}+0.5 \mathrm{Na}_{2} \mathrm{~S}\right.$ $+\mathrm{NaI}+\mathrm{LiI})$, so that there is no energetic driver for phase separation. Since no other stable phases exist between $\mathrm{Na}$ and $\mathrm{Na}_{2} \mathrm{O} / \mathrm{Na}_{2} \mathrm{~S} / \mathrm{NaI} / \mathrm{LiI},{ }^{68,69}$ one can conclude that $\mathrm{Na}_{3} \mathrm{LiS}_{0.5} \mathrm{O}_{0.5} \mathrm{I}_{2}$ does not react with the $\mathrm{Na}$ anode. This is consistent with the AIMD simulation more than $100 \mathrm{~K}$ above the melting temperature of sodium (Fig. S6a $\dagger$ ).

From an equilibrium point of view, equilibration associated with depletion of $\mathrm{Na}^{+}$typically involved with a high voltage cathode material can be investigated by ATAT simulation over $\mathrm{Na}_{3(1-y)} \mathrm{Li}_{1-x} \mathrm{~S}_{0.5} \mathrm{O}_{0.5} \mathrm{I}_{2}(0 \leq x, y \leq 1)$. The identified stable structures are shown in Fig. 9(b), with their corresponding electrochemical potential shown in Fig. 9(a). It is encouraging to note that the lattice mismatches between neighbouring layers are rather limited $(2.5-8 \%)$, which helps to maintain mechanical integrity when such an interfacial reaction occurs during service.

The three stable phases owing to sodium depletion from the optimized electrolyte $\mathrm{Na}_{3} \mathrm{LiS}_{0.5} \mathrm{O}_{0.5} \mathrm{I}_{2}$ are $\mathrm{NaLiS}_{0.5} \mathrm{O}_{0.5} \mathrm{I}_{2}, \mathrm{Na}_{0.25^{-}}$ $\mathrm{LiS}_{0.5} \mathrm{O}_{0.5} \mathrm{I}_{2}$ and $\mathrm{LiS}_{0.5} \mathrm{O}_{0.5} \mathrm{I}_{2}$. The layered structures are largely maintained throughout the sodium depletion process across

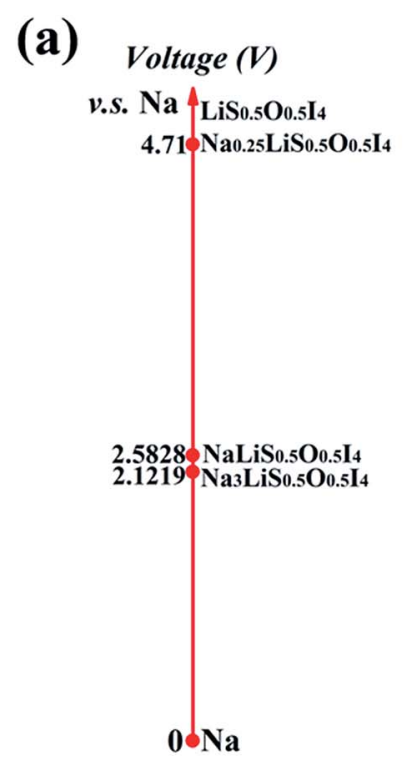

(b)

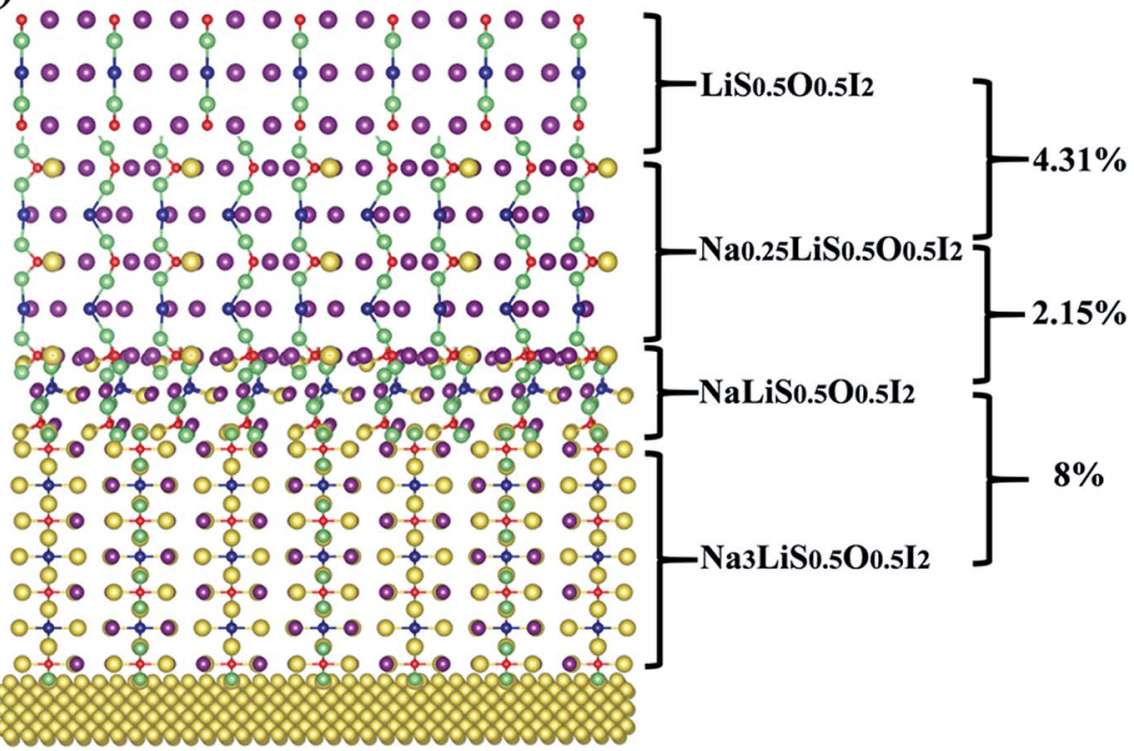

Fig. 9 Electrochemical potentials (a) for ground-state stable structures of $\mathrm{Na}_{3(1-y)} \mathrm{Li}_{1-x} \mathrm{~S}_{0.5} \mathrm{O}_{0.5} \mathrm{I}_{2}(0 \leq x, y \leq 1)$ from ATAT simulation. (b) Percentages on the right refer to lattice mismatches. 
the three phases, with electrochemical potential (calculated by eqn (2)) increasing with decreasing $\mathrm{Na}^{+}$content. As the redox potential of $\mathrm{Na}^{+} / \mathrm{Na}$ is $0.34 \mathrm{~V}$ higher than that of $\mathrm{Li}^{+} / \mathrm{Li}$, only sodium can deposit or dissolve at the anode, while the $\mathrm{Na}^{+}$and $\mathrm{Li}^{+}$hybrid electrolyte acts as an ion reservoir to supply or receive $\mathrm{Na}^{+} / \mathrm{Li}^{+}$during the discharge/charge process. The electrochemical window for the electrolyte $\mathrm{Na}_{3} \mathrm{LiS}_{0.5} \mathrm{O}_{0.5} \mathrm{I}_{2}$ is from 0 to $2.1219 \mathrm{~V}$, and the maximum oxidation voltage plateau reaches $4.71 \mathrm{~V}$ through sodium depletion over the $\mathrm{Na}_{0.25} \mathrm{LiS}_{0.5} \mathrm{O}_{0.5} \mathrm{I}_{2}-$ $\mid \mathrm{LiS}_{0.5} \mathrm{O}_{0.5} \mathrm{I}_{2}$ equilibration.

This means that $\operatorname{LiS}_{0.5} \mathrm{O}_{0.5} \mathrm{I}_{2}$ and metallic sodium can be used as an electrochemically compatible cathode and anode with the $\mathrm{Na}_{3} \mathrm{LiS}_{0.5} \mathrm{O}_{0.5} \mathrm{I}_{2}$ to form a solid sodium battery of $\mathrm{Na}\left|\mathrm{Na}_{3} \mathrm{LiS}_{0.5} \mathrm{O}_{0.5} \mathrm{I}_{2}\right| \mathrm{LiS}_{0.5} \mathrm{O}_{0.5} \mathrm{I}_{2}$, with evolution of interfacial solid phases being mechanically and electrochemically compatible with the electrolyte and the cathode. ${ }^{16,61,70}$ The density of states (DOS) for $\mathrm{LiS}_{0.5} \mathrm{O}_{0.5} \mathrm{I}_{2}$ with metallic characteristics is displayed in Fig. $\mathrm{S} 8, \uparrow$ which indicates that it is a good electronic conductor as a cathode.

In an optimized battery structure, one can make use of a graded battery structure, with each layer being a stable phase, as shown in Fig. 10. The Li content is maintained in such a graded cell, with the change of Na content owing to charging/ discharging leading to $\mathrm{NaLi}_{0.5} \mathrm{O}_{0.5} \mathrm{I}_{2}$ and $\mathrm{Na}_{0.25} \mathrm{LiS}_{0.5} \mathrm{O}_{0.5} \mathrm{I}_{2}$. Such a cell construction is thus thermodynamically compatible in service. Mechanical integrity can also be readily maintained in such a graded solid battery, owing to the limited lattice mismatch between the layers of materials. The high contents of sodium across materials in the graded layers are helpful to deliver high capacity for the full battery. As is indicated in Fig. 10, the corresponding capacities for $\mathrm{Na}_{3} \mathrm{LiS}_{0.5} \mathrm{O}_{0.5} \mathrm{I}_{2}$, $\mathrm{NaLiS}_{0.5} \mathrm{O}_{0.5} \mathrm{I}_{2}$, and $\mathrm{Na}_{0.25} \mathrm{LiS}_{0.5} \mathrm{O}_{0.5} \mathrm{I}_{2}$ are $302.6 \mathrm{~mA} \mathrm{~h} \mathrm{~g}{ }^{-1}$, $173.91 \mathrm{~mA} \mathrm{~h} \mathrm{~g}^{-1}$, and $115.15 \mathrm{~mA} \mathrm{~h} \mathrm{~g}^{-1}$. The theoretical limit for energy density of a full cell, on the basis of balanced capacities, is over $320 \mathrm{~W} \mathrm{~h} \mathrm{~kg}{ }^{-1}$ (the maximum energy density of the materials system, undergoing equilibration over $\mathrm{Na}$ depletion,

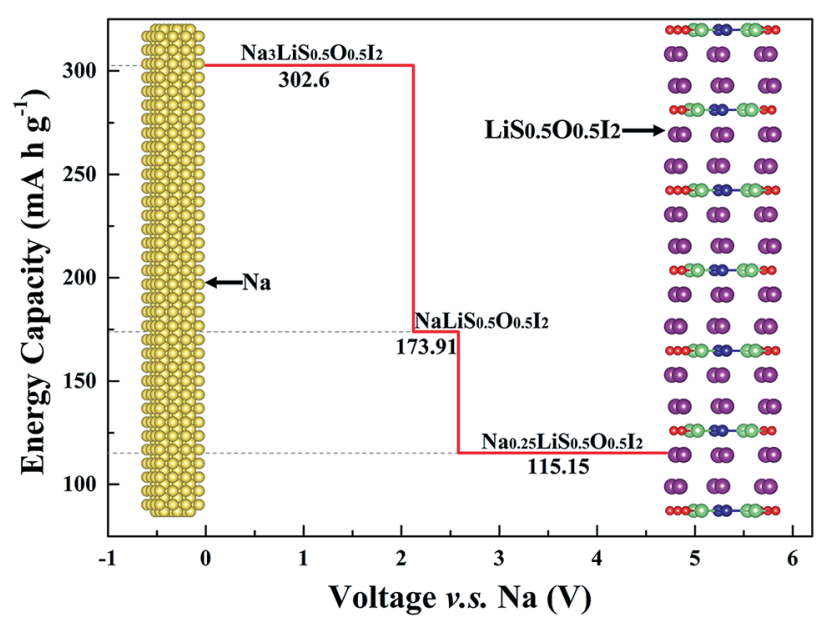

Fig. 10 Set up of a full battery based on graded layers of materials, with capacity plotted against corresponding electrochemical potential. The area below the red lines is representative of the theoretical limit for energy density, being over $967 \mathrm{~W} \mathrm{~h} \mathrm{~kg}^{-1}$.
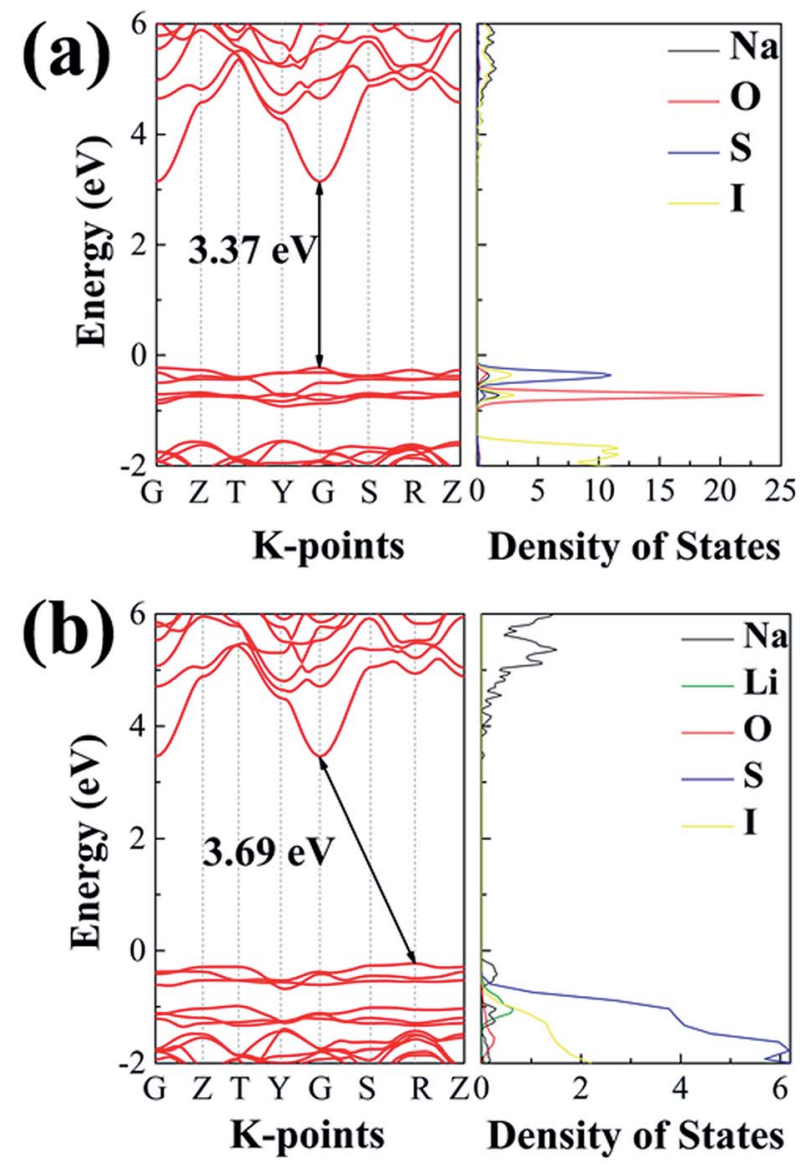

Fig. 11 The projected density of states calculated using the HSEO6 functional: (a) $\mathrm{Na}_{4} \mathrm{~S}_{0.5} \mathrm{O}_{0.5} \mathrm{I}_{2} ;$ (b) $\mathrm{Na}_{3} \mathrm{LiS}_{0.5} \mathrm{O}_{0.5} \mathrm{I}_{2}$.

corresponds to the area under the capacity lines in Fig. 10, being $967 \mathrm{~W} \mathrm{~h} \mathrm{~kg}^{-1}$ ). Such a hybrid rechargeable ion battery system is of great potential to outperform the current state-ofthe-art battery systems, so that high battery voltage and capacity can be achieved at the same time.

\section{Bandgaps}

While a SSE needs to be highly conductive to $\mathrm{Na}^{+}$ions, it should be insulating to electrons, so as to avoid self-discharging across the electrodes. Fig. 11 summarizes electronic band structures as well as density of states (DOS) for the ionic conductors of interest in this work. Both electrolytes are of wide energy gaps, being $3.37 \mathrm{eV}$ for $\mathrm{Na}_{4} \mathrm{~S}_{0.5} \mathrm{O}_{0.5} \mathrm{I}_{2}$ and $3.69 \mathrm{eV}$ for $\mathrm{Na}_{3} \mathrm{LiS}_{0.5} \mathrm{O}_{0.5} \mathrm{I}_{2}$, which are adequate for solid electrolytes. In comparison, such band gaps are considerably larger than those of the wellrecognized SSE materials. The band gap for the landmark LGPS is only $2.68 \mathrm{eV},{ }^{60}$ as shown in Fig. S9. $\dagger$ The band gaps for $\mathrm{Li}_{6} \mathrm{PS}_{5} \mathrm{Cl}$ and $\mathrm{Na}_{11} \mathrm{Sn}_{2} \mathrm{PS}_{12}$ are $3.1 \mathrm{eV}$ (ref. 18) and $2.87 \mathrm{eV},{ }^{71}$ respectively.

\section{Conclusions}

Systematic modelling has been carried out to design fast $\mathrm{Na}^{+}$ ion conductors through optimizing materials chemistry over 
lattice sites of a layered anti-perovskite like structure, $\mathrm{Na}_{4} \mathrm{OI}_{2}$. This results in the discovery of a superb solid electrolyte $\mathrm{Na}_{3}$ $\mathrm{LiS}_{0.5} \mathrm{O}_{0.5} \mathrm{I}_{2}$, which exerts extremely low activation energy for $\mathrm{Na}^{+}$ diffusion, thus permitting a room temperature $\mathrm{Na}^{+}$conductivity of over $6.3 \mathrm{mS} \mathrm{cm}^{-1}$.

The optimized electrolyte is compatible with the sodium anode both thermodynamically and electrochemically. Depletion of sodium at elevated voltages leads to formation of stable compounds suitable for compatible cathode materials. This enables construction of high capacity full batteries based on graded layers covering electrolyte and cathodes. The theoretical energy density for a graded battery is over $320 \mathrm{~W} \mathrm{~h} \mathrm{~kg}^{-1}$, which is fundamental for high performance solid sodium ion batteries.

\section{Conflicts of interest}

There are no conflicts to declare.

\section{Acknowledgements}

This work is supported in part by the Zhengzhou Materials Genome Institute, the National Natural Science Foundation of China (No. 51001091, 111174256, 91233101, 51602094, 51602290, 11274100), and the Fundamental Research Program from the Ministry of Science and Technology of China (no. 2014CB931704).

\section{Notes and references}

1 M. Armand and J. M. Tarascon, Nature, 2008, 451, 652-657.

2 B. Dunn, H. Kamath and J. M. Tarascon, Science, 2011, 334, 928-935.

3 B. Scrosati, J. Hassoun and Y.-K. Sun, Energy Environ. Sci., 2011, 4, 3287-3295.

4 V. Palomares, P. Serras, I. Villaluenga, K. B. Hueso, J. Carretero-González and T. Rojo, Energy Environ. Sci., 2012, 5, 5884-5901.

5 A. Eftekhari, J. Power Sources, 2004, 126, 221-228.

6 X. Fan, R. R. Gaddam, N. A. Kumar and X. S. Zhao, Adv. Energy Mater., 2017, 7, 1700317.

7 Z. Wang and G. Shao, J. Mater. Chem. A, 2018, 6, 6830-6839.

8 L. Zhang, L. Chen, X. Zhou and Z. Liu, Adv. Energy Mater., 2015, 5, 1400930.

9 N. Nitta, F. Wu, J. T. Lee and G. Yushin, Mater. Today, 2015, 18, 252-264.

10 M. Tatsumisago, M. Nagao and A. Hayashi, J. Asian Ceram. Soc., 2013, 1, 17-25.

11 K. Takada, Acta Mater., 2013, 61, 759-770.

12 Q. Wang, P. Ping, X. Zhao, G. Chu, J. Sun and C. Chen, J. Power Sources, 2012, 208, 210-224.

13 C. Julien and G. A. Nazri, Solid State Batteries: Materials Design and Optimization, Springer US, 1994.

14 Y. Lu, L. Li, Q. Zhang, Z. Niu and J. Chen, Joule, 2018, 2, 1-24.

15 J. Y. Hwang, S. T. Myung and Y. K. Sun, Chem. Soc. Rev., 2017, 46, 3529-3614.
16 Y. Yu, Z. Wang and G. Shao, J. Mater. Chem. A, 2018, 6, 19843-19852.

17 A. Kuhn, V. Duppel and B. V. Lotsch, Energy Environ. Sci., 2013, 6, 3548-3552.

18 Z. Wang and G. Shao, J. Mater. Chem. A, 2017, 5, 21846-21857.

19 W. D. Richards, T. Tsujimura, L. J. Miara, Y. Wang, J. C. Kim, S. P. Ong, I. Uechi, N. Suzuki and G. Ceder, Nat. Commun., 2016, 7, 11009.

20 Z. Zhang, E. Ramos, F. Lalère, A. Assoud, K. Kaup, P. Hartman and L. F. Nazar, Energy Environ. Sci., 2018, 11, 87-93.

21 S. Wenzel, S. Randau, T. Leichtweiß, D. A. Weber, J. Sann, W. G. Zeier and J. Janek, Chem. Mater., 2016, 28, 2400-2407.

22 A. Hayashi, K. Noi, N. Tanibata, M. Nagao and M. Tatsumisago, J. Power Sources, 2014, 258, 420-423.

23 A. Hayashi, K. Noi, A. Sakuda and M. Tatsumisago, Nat. Commun., 2012, 3, 856.

24 S.-H. Bo, Y. Wang, J. C. Kim, W. D. Richards and G. Ceder, Chem. Mater., 2016, 28, 252-258.

25 L. Zhang, K. Yang, J. Mi, L. Lu, L. Zhao, L. Wang, Y. Li and H. Zeng, Adv. Energy Mater., 2015, 5, 1501294.

26 H. Wang, Y. Chen, Z. D. Hood, G. Sahu, A. S. Pandian, J. K. Keum, K. An and C. Liang, Angew. Chem., 2016, 128, 8693-8697.

27 A. Banerjee, K. H. Park, J. W. Heo, Y. J. Nam, C. K. Moon, S. M. Oh, S. T. Hong and Y. S. Jung, Angew. Chem., 2016, 128, 9634-9638.

28 Y. Zhu, X. He and Y. Mo, ACS Appl. Mater. Interfaces, 2015, 7, 23685-23693.

29 Y. Wang, Q. Wang, Z. Liu, Z. Zhou, S. Li, J. Zhu, R. Zou, Y. Wang, J. Lin and Y. Zhao, J. Power Sources, 2015, 293, 735-740.

30 H. Sabrowsky, K. Hippler, S. Sitta, P. Vogt and L. Walz, Acta Crystallogr., 1990, 46, 368-369.

31 H. Sabrowsky, K. Hippler and P. Vogt, Z. Naturforsch., B: J. Chem. Sci., 1989, 44, 373-374.

32 J. Zhu, Y. Wang, S. Li, J. W. Howard, J. Neuefeind, Y. Ren, H. Wang, C. Liang, W. Yang, R. Zou, C. Jin and Y. Zhao, Inorg. Chem., 2016, 55, 5993-5998.

33 Z. Wang, H. Xu, M. Xuan and G. Shao, J. Mater. Chem. A, 2018, 6, 73-83.

34 Z. Wang, B. Lei, X. Xia, Z. Huang, K. P. Homewood and Y. Gao, J. Phys. Chem. C, 2018, 122, 2589-2595.

35 M. Xuan, W. Xiao, H. Xu, Y. Shen, Z. Li, S. Zhang, Z. Wang and G. Shao, J. Mater. Chem. A, 2018, 6, 19231-19240.

36 G. Kresse and J. Hafner, Phys. Rev. B: Condens. Matter Mater. Phys., 1993, 47, 558-561.

37 G. Kresse and J. Hafner, Phys. Rev. B: Condens. Matter Mater. Phys., 1994, 49, 14251-14269.

38 P. E. Blöchl, Phys. Rev. B: Condens. Matter Mater. Phys., 1994, 50, 17953-17979.

39 G. Kresse and D. Joubert, Phys. Rev. B: Condens. Matter Mater. Phys., 1999, 59, 1758-1775.

40 G. Kresse and J. Hafner, Phys. Rev. B: Condens. Matter Mater. Phys., 1993, 48, 13115-13118.

41 J. P. Perdew, K. Burke and M. Ernzerhof, Phys. Rev. Lett., 1996, 77, 3865-3868. 
42 G. Shao, J. Phys. Chem. C, 2009, 113, 6800-6808.

43 G. Shao, J. Phys. Chem. C, 2008, 112, 18677-18685.

44 X. Han, K. Song, L. Lu, Q. Deng, X. Xia and G. Shao, J. Mater. Chem. C, 2013, 1, 3736-3746.

45 X. Han and G. Shao, J. Mater. Chem. C, 2015, 3, 530-537.

46 J. Heyd, G. E. Scuseria and M. Ernzerhof, J. Chem. Phys., 2003, 118, 8207-8215.

47 J. Heyd, G. E. Scuseria and M. Ernzerhof, J. Chem. Phys., 2006, 124, 219906.

48 A. R. Oganov and C. W. Glass, J. Chem. Phys., 2006, 124, 244704.

49 C. W. Glass, A. R. Oganov and N. Hansen, Comput. Phys. Commun., 2006, 175, 713-720.

50 K. Parlinski, Z. Q. Li and Y. Kawazoe, Phys. Rev. Lett., 1997, 78, 4063-4066.

51 A. Togo, F. Oba and I. Tanaka, Phys. Rev. B: Condens. Matter Mater. Phys., 2008, 78, 134106.

52 T. D. Huan, V. N. Tuoc and N. V. Minh, Phys. Rev. B, 2016, 93, 094105.

53 F. Brivio, J. M. Frost, J. M. Skelton, A. J. Jackson, O. J. Weber, M. T. Weller, A. R. Goñi, A. M. A. Leguy, P. R. F. Barnes and A. Walsh, Phys. Rev. B: Condens. Matter Mater. Phys., 2015, 92, 144308.

54 Z. Deng, Z. Zhu, I.-H. Chu and S. P. Ong, Chem. Mater., 2017, 29, 281-288.

55 M. V. Agnihotri, S. H. Chen, C. Beck and S. J. Singer, J. Phys. Chem. B, 2014, 118, 8170-8178.

56 X. Zhao, Z. Zhang, X. Zhang, B. Tang, Z. Xie and Z. Zhou, J. Mater. Chem. A, 2018, 6, 2625-2631.

57 G. L. W. Hart and R. W. Forcade, Phys. Rev. B: Condens. Matter Mater. Phys., 2008, 77, 224115.
58 A. V. D. Walle and G. Ceder, J. Phase Equilib., 2002, 23, 348359.

59 S. P. Ong, Y. Mo, W. D. Richards, L. Miara, H. S. Lee and G. Ceder, Energy Environ. Sci., 2013, 6, 148-156.

60 M. H. Braga, J. A. Ferreira, V. Stockhausen, J. E. Oliveira and A. El-Azab, J. Mater. Chem. A, 2014, 2, 5470-5480.

61 Y. Zhu, X. He and Y. Mo, J. Mater. Chem. A, 2016, 4, 32533266.

62 C. Liang, D. Zhao, Y. Li, X. Li, S. Peng, G. Shao and G. Xing, Energy Environ. Mater., 2018, 1, 221-231.

63 T. Takeguchi, T. Yamanaka, H. Takahashi, H. Watanabe, T. Kuroki, H. Nakanishi, Y. Orikasa, Y. Uchimoto, H. Takano, N. Ohguri, M. Matsuda, T. Murota, K. Uosaki and W. Ueda, J. Am. Chem. Soc., 2013, 135, 11125-11130.

64 R. E. Schaak and T. E. Mallouk, Chem. Mater., 2002, 14, 14551471.

65 Y. Zhang, Y. Zhao and C. Chen, Phys. Rev. B: Condens. Matter Mater. Phys., 2013, 87, 134303.

66 Q. Huang, J. Liu, S. Xu, P. Wang, D. G. Ivey, B. Huang and W. Wei, Chem. Mater., 2018, 30, 4728-4737.

67 K. Du, J. Zhu, G. Hu, H. Gao, Y. Li and J. B. Goodenough, Energy Environ. Sci., 2016, 9, 2575-2577.

68 Y. Tian, T. Shi, W. D. Richards, J. Li, J. C. Kim, S.-H. Bo and G. Ceder, Energy Environ. Sci., 2017, 10, 1150-1166.

69 Y. Tian, Y. Sun, D. C. Hannah, Y. Xiao, H. Liu, K. W. Chapman, S.-H. Bo and G. Ceder, Joule, 2019, DOI: 10.1016/j.joule.2018.12.019.

70 H. Xu, Y. Yu, Z. Wang and G. Shao, J. Mater. Chem. A, 2019, 7, 5239-5247.

71 J. Liu, Z. Lu, M. B. Effat and F. Ciucci, J. Power Sources, 2019, 409, 94-101. 